\title{
REGULARITY FOR THE NAVIER-STOKES-FOURIER SYSTEM
}

\author{
LUISA CONSIGLIERI
}

Abstract. We prove the existence of strong 2-dimensional solutions for two Cauchy-Dirichlet problems to the Navier-Stokes-Fourier system which characterizes the Newtonian fluids under heat-conducting effects. The nonstationary Navier-Stokes system for an incompressible homogeneous fluid with temperature dependent viscosity is completed by the equation of balance of energy which includes the term of dissipative heating. The regularity of solutions to the problems under study is proved through compactness methods and fixed point arguments, instead assuming the existence of weak solutions to the problems.

Mathematics subject classification (2000): 35Q30, 80A20, 35K55, 76 D03.

Keywords and phrases: Navier-Stokes-Fourier system, Joule effect, Schauder theorem, apriori estimates, interpolative inequalities.

\section{REFERENCES}

[1] S.N. Antontsev, A.V. Kazhikhov And V.N. Monakhov, Boundary value problems in mechanics of nonhomogeneous fluids, Studies in Mathematics and its Applications 22, North-Holland, 1990.

[2] A. ARKhipova, Global solvability of the Cauchy-Dirichlet problem for nondiagonal parabolic systems with variational structure in the case of two spatial variables, J. Math. Sci., 92, 6 (1998), 42314255 .

[3] A. Bermúdez de Castro, Continuum Thermomechanics, Progress in Mathematical Physics , 43, Birkhäuser 2005.

[4] T. Clopeau And A. Mikelić, Nonstationary flows with viscous heating effects, ESAIM Proc., 2 (1997), 55-63.

[5] L. CONSIGLIERI, Weak solutions for a class of non-Newtonian fluids with energy transfer, J. Math. Fluid Mech., 2, 3 (2000), 267-293.

[6] L. Consigleri, Friction boundary conditions on thermal incompressible viscous flows, Ann. Mat. Pura Appl. IV, 187, 4 (2008), 647-665.

[7] L. CONSIGLIERI AND T. SHILKIn, Regularity to stationary weak solutions for generalized Newtonian fluids with energy transfer, Zapiski Nauchnyh Seminarov POMI, 271 (2000), 122-150.

[8] J. I. Diaz And G. Galiano, Existence and uniqueness of solutions to the Boussinesq system with nonlinear thermal diffusion, Report Modelling, Analysis and Simulation (MAS) MAS-R9722 September 30, 1997.

[9] Y. GIGA, Solutions for semilinear parabolic equations in $L^{p}$ and regularity of weak solutions of the Navier-Stokes system, J. Differ. Equations, 61 (1986), 186-212.

[10] P. KAPLICKÝ, J. MÁLEK AND J. STARÁ, Global-in-time Hölder continuity of the velocity gradients for fluids with shear-dependent viscosities, NoDEA, Nonlinear Differ. Equ. and Appl., 9, 2 (2002), $175-195$.

[11] O. A. LADYZHENSKAYA, Mathematical problems in the dynamics of a viscous incompressible fluid, 2nd rev. aug. ed., "Nauka", Moscow, 1970: English transl. of 1st ed.,The mathematical theory of viscous incompressible flow, Gordon and Breach, New York 1969.

[12] O. A. Ladyzhenskaya, V. A. Solonnikov And N. N. Uraltseva, Linear and quasilinear equations of parabolic type, Translations of Mathematical Monographs, Vol. 23 American Matematical Society, Providence, R.I., 1967. 
[13] R. LEWANDOWSKI, The mathematical analysis of the coupling of a turbulent kinetic energy equation to the Navier-Stokes equation with an eddy viscosity, Nonlinear Anal., Theory Methods Appl., 28, 2 (1997), 393-417.

[14] J. L. Lions, Quelques méthodes de résolution des problèmes aux limites non linéaires, Dunod et Gauthier-Villars, Paris, 1969.

[15] P. L. Lions, Mathematical topics in fluid mechanics, 1, Oxford Lecture Series in Mathematics and its Applications, The Clarendon Press Oxford University Press, New York, 1996.

[16] S. A. LORCA AND J. L. BoldRINI, The initial value problem for a generalized Boussinesq model, Nonlinear Anal., Theory Methods Appl., 36, 4 (1999), 457-480.

[17] J. MÁleK, J. NeČAs, M. RoKyta AND M. RUŽIČKA, Weak and Measure-valued solutions to evolutionary PDEs, Chapman and Hall, London, 1996.

[18] B. Mohammadi And O. Pironneau, Analysis of the K-Epsilon turbulence model, Research in Applied Mathematics. Wiley/Masson, 1994.

[19] J. NAUMANn, On the existence of weak solutions to the equations of non-stationary motion of heatconducting incompressible viscous fluids, Math. Meth. Appl. Sci., 29 (2006), 1883-1906.

[20] J. NEČAS AND V. Š VERÁK, On regularity of solutions of nonlinear parabolic systems, Ann. Sc. Norm. Super. Pisa, 18, 1 (1991), 1-11.

[21] L. Nirenberg, On elliptic partial differential equations, Ann. Sc. Norm. Super. Pisa, 13 (1959), $115-162$.

[22] R. ROSSI AND G. SAVARÉ, Tightness, integral equicontinuity and compactness for evolution problems in Banach spaces, Ann. Sc. Norm. Super. Pisa, 5, 2 (2003), 395-431.

[23] T. RoubíčEK, On non-Newtonian fluids with energy transfer, J. Math. Fluid Mech., 9 (2007), 1-16.

[24] J. Simon, Compact sets in the space, Ann. Mat. Pura Appl., 146, 4 (1987), 65-96.

[25] R. Temam, Navier Stokes equations: theory and numerical analysis, North-Holland, Amsterdam, 1979. 